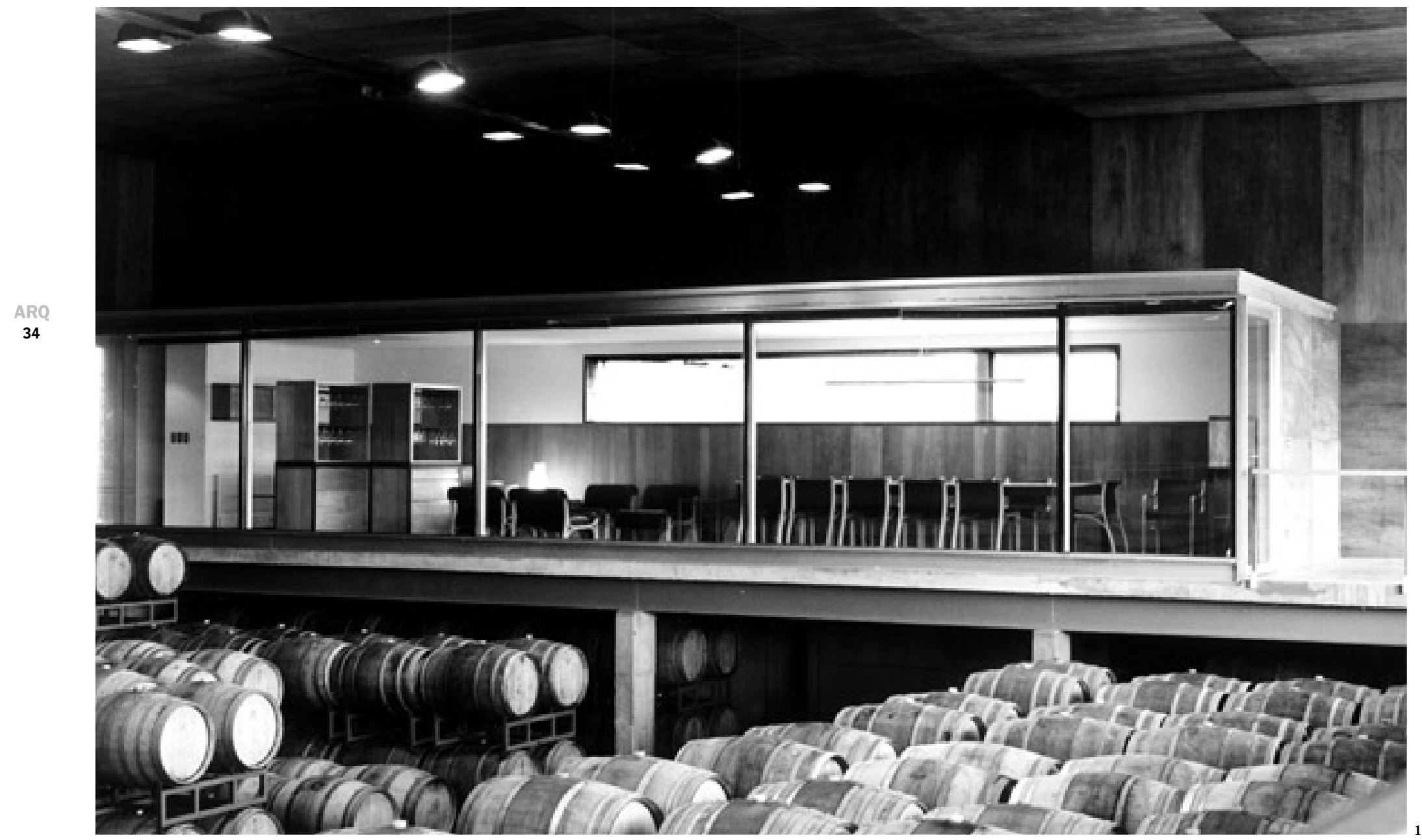

Paulina Courard

\title{
Sala de degustación
}

El programa de estos edificios industriales ha incorporado un espacio de escala menor pero de un uso intenso y expuesto: la sala de degustaciones, donde trabaja el enólogo y se recibe a los visitantes. Es aquí donde el problema de la identidad corporativa se traslada de la vista de una fachada desde la carretera a asuntos táctiles, y de paso incorpora el tema de la hospitalidad; en este caso, recuperando elementos de oficios tradicionales en un espacio neutro y despejado. Palabras clave: Arquitectura-Chile, interiorismo, sala de degustación, viñas.

The activities in these industrial buildings bave included a smaller-scale space with a bighly public and intensive use -the wine tasting room, where the enologist works and receives visitors. Here the issue of corporate identity shifts from a façade seen from the highway to tactile matters, and in passing raises the issue of hospitality. In this case, elements of traditional skills are recovered, in a clean, neutral space.

Key words: Architecture-Chile, interior design, tastings room, wineries.
El encargo de equipar la sala de degustación de la Viña Cono Sur (ubicada al interior de la bodega de barricas de la viña, de la arquitecta Cecilia Puga) se enfrentó con un presupuesto ajustado, mandando a hacer objetos a medida con diseño propio -mesa, contenedores y muebles expositores-, y adquiriendo elementos existentes de otros diseñadores también realizados en Chile. Estos últimos son: sillas y sillones de Cristián Valdés, alfombra de Huaquén, y cerámicas hechas a mano de Celinda Céspedes, de Vichuquén. Sólo se usaron dos colores: negro en cueros y metales, que se replica en la quema de las cerámicas, y color madera en el algarrobo negro y la piedra de Huasco.
Se propuso una sala de degustación en torno a una mesa de $1.2 \times 3.6 \mathrm{~m}$ hecha de estructura metálica de perfiles Gerdau Aza L 80 x 80 x 8 mm más un bastidor separador en perfiles L $50 \times 50 \times 4 \mathrm{~mm}$, con los cantos rectos y los espesores del metal hacia las caras vistas.

La cubierta consiste en tres pares de planchas de piedra Huasco de un mismo bloque escogido especialmente, con sus caras opuestas pulidas, y todos los cantos pulidos rectos. Los muebles contenedores y expositores (que recibirían copas, botellas de vino y otros utensilios para la cata) se realizaron en madera de jequitiba de $45 \mathrm{~mm}$ de espesor, y perfiles Gerdau Aza de 30 × 30 × 5 mm. ARQ

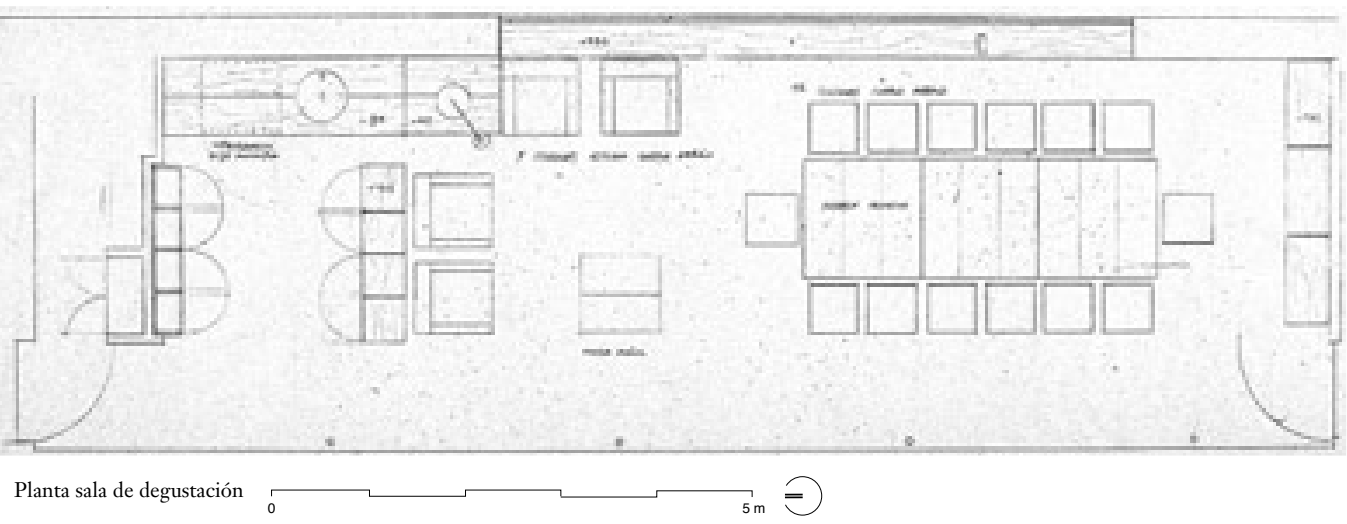


1 Vista del volumen de la sala de degustaciones desde

interior de la bodeg

2 Vista general del interio

de la sala

3 Cerámica de Vichuquén y

4 Detalle de la mesa de cata

metal y piedr

5 Mesa de cata

6 Corte longitudinal y croquis de la propuesta cubierta de piedra de Huasco
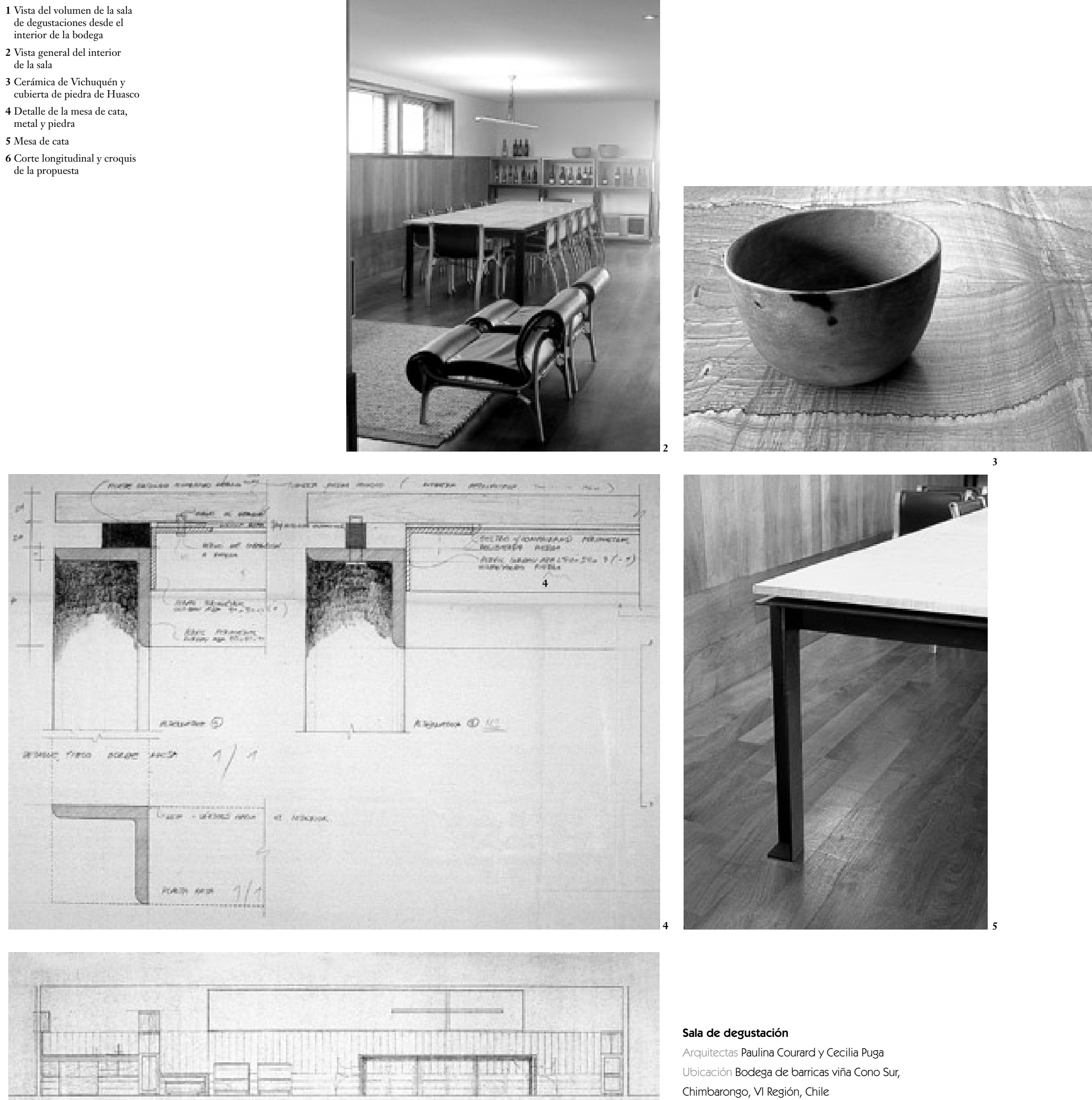

Sala de degustación

Arquitectas Paulina Courard y Cecilia Puga

Ubicación Bodega de barricas viña Cono Sur,

Chimbarongo, VI Región, Chile

Mandante Viña Cono Sur. Adolfo Hurtado, enólogo

Contratista José González

Construcción estructuras metálicas Aldo Bril, Multimetal

Mobiliario en madera Taller Hermanos Maldonado

Mobiliario en cuero Cristián Valdés

Cubiertas en piedra Mármoles Cedolín

|luminación Pascal Chautard

Superficie construida $50 \mathrm{~m}^{2}$

Superficie proyecto 2002

Año construcción 2002

Fotografía Paulina Courard 